\title{
The relative efficiency in the blending of strategic dimensions utilized in the generation of customer satisfaction in the LTL motor carrier industry
}

\author{
Carl A. Scheraga \\ Fairfield University, cscheraga@fairfield.edu
}

Follow this and additional works at: https://digitalcommons.fairfield.edu/business-facultypubs

Copyright 2005 Transportation Research Forum

All rights reserved. http://www.trforum.org/journal/.

\section{Repository Citation}

Scheraga, Carl A., "The relative efficiency in the blending of strategic dimensions utilized in the generation of customer satisfaction in the LTL motor carrier industry" (2005). Business Faculty Publications. 139.

https://digitalcommons.fairfield.edu/business-facultypubs/139

\section{Published Citation}

Scheraga, Carl A. "The relative efficiency in the blending of strategic dimensions utilized in the generation of customer satisfaction in the LTL motor carrier industry." In Journal of the Transportation Research Forum, vol. 44, no. 1. (Spring 2005), pp. 75-88.

This item has been accepted for inclusion in DigitalCommons@Fairfield by an authorized administrator of DigitalCommons@Fairfield. It is brought to you by DigitalCommons@Fairfield with permission from the rightsholder(s) and is protected by copyright and/or related rights. You are free to use this item in any way that is permitted by the copyright and related rights legislation that applies to your use. For other uses, you need to obtain permission from the rights-holder(s) directly, unless additional rights are indicated by a Creative Commons license in the record and/or on the work itself. For more information, please contact digitalcommons@fairfield.edu. 
The Relative Efficiency in the Blending of Strategic Dimensions Utilized in the Generation of Customer Satisfaction in the LTL Motor Carrier Industry

Author(s): Carl A. Scheraga

Source: Journal of the Transportation Research Forum, Vol. 44, No. 1 (Spring 2005), pp. 75-88

Published by: Transportation Research Forum

Stable URL: http://www.trforum.org/journal

The Transportation Research Forum, founded in 1958, is an independent, nonprofit organization of transportation professionals who conduct, use, and benefit from research. Its purpose is to provide an impartial meeting ground for carriers, shippers, government officials, consultants, university researchers, suppliers, and others seeking exchange of information and ideas related to both passenger and freight transportation. More information on the Transportation Research Forum can be found on the Web at www.trforum.org. 


\section{The Relative Efficiency in the Blending of Strategic Dimensions Utilized in the Generation of Customer Satisfaction in the LTL Motor Carrier Industry}

This preliminary study utilizes a data envelopment methodology to assess the strategic orientations of LTL motor carriers and their impact on customer satisfaction and firm profitability. Strategic orientations are described in terms of seven dimensions previously identified in the motor carrier literature. The study demonstrates that there are "best practice" configurations of the intensities of these strategic dimensions that most efficiently generate the maximum levels of customer satisfaction and perceived levels of service quality. It is shown how the data envelopment methodology provides motor carriers with a means of benchmarking their strategic orientations as well as identifying the competitors against whom such benchmarking should occur.

\section{by Carl A. Scheraga}

\section{Customer Satisfaction}

Motor carrier profitability is irrevocably linked to a firm's ability to provide necessary and satisfactory services to its customers. Not surprisingly, the literature on motor carrier customer service is quite extensive. Work by Chow and Poist (1984), McGinnis (1990), Kleinsorge et al. (1991), Lambert et al. (1993), Holcomb and Manrodt (2000), and Premeaux (2002) has identified dimensions of service quality that form the basis for the measures or critical areas of service utilized in the large annual Quest for Quality Survey conducted by the Reed Research Group for Logistics Management. Five critical areas are identified: performance, value, information technology, customer service, and equipment and operations. The components of the performance measure include on-time delivery and pick-up, consistent and dependable schedules and transit times, and equipment availability. The value measure includes such components as competitive rates, prices commensurate with required service levels, and the simplicity of pricing. The critical area of information technology is captured by the ability to trace and track shipments and capabilities related to EDI, the Internet, and electronic commerce. Customer service is composed of the components of the abilities to promptly settle claims, trace and ex- pedite shipments, and solve problems promptly and courteously. Finally, the level of the measure for equipment and operations is determined by the availability of equipment and its condition, the carrier's safety record, and the incidence of loss and damage claims.

However, an understanding of customer needs is not sufficient to guarantee customer satisfaction. The researcher must additionally understand how customers prioritize their needs and how such prioritization affects product and/ or service requirements. A methodology developed by Kano (1993) identifies four categories of customer needs. They are must have, linear satisfier, delighter, and indifferent. Must have needs are those that are routinely expected by the customer and are taken as a given by the customer. Increasing fulfillment of these needs does not provide increasing levels of customer satisfaction. However, if they are not fulfilled the customer will be very dissatisfied. Linear satisfier needs are those that display a positive linear or proportional relationship between the level of fulfillment of these needs and customer satisfaction. Delighter needs are not expected or anticipated by the customer. Therefore, non-fulfillment of these needs does not cause dissatisfaction. However, when such needs are fulfilled there is a more than proportional positive satisfaction response from the customer. Indif- 
ferent needs are those whose fulfillment or lack of fulfillment provides neither satisfaction nor dissatisfaction to the customer. The Quest for Quality Survey recognizes the phenomena described by the Kano model and seeks to capture it by the weighted-score methodology described below.

\section{The Dimensions of Operating Strategy}

As noted above, after the researcher has identified how customers prioritize their needs, they must investigate how product or service requirements are defined and pursued to generate customer satisfaction. More specifically, in the context of the motor carrier industry, this means that one needs to identify the strategic focus or foci of individual motor carriers. These foci effectively represent how motor carriers have defined the requirements or structure of the services they provide. Having done this, the researcher can then investigate whether individual motor carriers have constructed operating strategies that generate the desired level of customer satisfaction.

In his seminal work, Michael Porter (1980) developed the paradigm of three generic strategies for creating a competitive advantage. A firm pursuing a position of cost leadership will emphasize efficiency to reduce costs thus being able to underprice competitors. The focus of such a strategy is one of low margins and high volume. A firm with a strategic orientation towards differentiation seeks to produce a product or service that embodies distinctive qualities for which customers are willing to pay a premium price. The third strategy is a niche-seeking one. This strategy seeks to identify a small part of the market not served by direct competitors of the firm. The firm is able to charge a premium price for a high-quality product desired by this small market segment, that is, volume of sales will be low, but margins high.

Feitler et al. (1997) note that seven dimensions have been used to capture the strategic orientation of LTL motor carriers. Four of these dimensions directly draw their inspiration from the Porter framework. Smith et al. (1992) captured a carrier's focus on cost by measuring total operating expenses per mile. Corsi and Grimm (1989) investigated the related dimension of ef- ficiency by examining annual miles per truck. A carrier's ability to charge a premium price for trucking services is reflected in the dimension Corsi et al. (1991) measured by total LTL revenue per ton. Scheraga et al. (1994) measure a carrier's LTL niche focus by the percentage of LTL revenue as a percentage of total revenue.

Three additional dimensions have also been discussed in the literature. Scheraga et al. (1994) investigated the impact of a motor carrier's financial mobility on its performance. This dimension captures the amount of risk assumed by a motor carrier in its management of its capital resources. The measure utilized to capture this dimension is the total debt-to-equity ratio. Smith et al. (1990) and Corsi et al. (1991) measure the service dimension by average employee compensation. They argue that higher-paid employees should provide customers with better service. The final dimension of size, reflecting economies of scale and scope, as discussed by Child (1974) and Scheraga et al. (1994) is represented by total operating revenues.

An observation must be made with regard to the variable measuring the service dimension, average employee compensation. It might be argued that rather than higher-paid employees being motivated to provide customers with better quality service, that such wages are the result of employees working in union firms. The assumption that higher wages are associated with a better level of service follows from previous research (Smith et al., 1990) that demonstrates through factor analysis that this variable was included with other measures in an overall service dimension factor.

The focus of this empirical investigation is to investigate two propositions. The first is that motor carriers in the sample of this study had targeted particular assessed levels of the five critical areas found in the Quest for Quality Survey and had chosen strategic orientations (combinations of levels or intensities of strategic dimensions) that most efficiently achieved said levels. The second proposition is that the diversity of strategic orientations of motor carriers in the sample reflects the fact that some carriers in the sample were generating levels of the five critical areas, as evaluated by customer, with inefficient combinations of strategic orientations. If the latter is the case, a restructuring of the strategic orienta- 
tions of inefficient motor carriers should lead to higher levels of performance on the critical areas of the survey.

Specifically, motor carriers operating with inefficient combinations of strategic dimension intensities are identified. Having identified these inefficient motor carriers, the necessary reductions to particular strategic dimension intensities are calculated in order for these firms to achieve efficient strategic profiles. The relationship between firms' level of efficiency and financial performance is also investigated.

It must be stressed that the purpose of this empirical investigation is not to identify a single best combination of strategic foci. Rather, the research employs the Porter framework which allows for a broad spectrum of combination strategies. However, what is being investigated is whether a given motor carrier in the sample, having chosen its combination strategy, is pursuing such a strategy in a relatively efficient manner.

\section{THE MODEL}

As discussed above, Porter's notion of three generic strategies for producers suggests that customers' demand for motor carrier service is a function of price and quality of service. This is analogous to the cost-quality arena of competition described by D'Aveni (1994). That is, in deciding upon a generic strategy to pursue, a firm effectively chooses to target a desired combination of price and quality by which it will define itself in the marketplace. This determines the realized demand by customers for its services. Thus the firm has two categories of outputs. The first is quality performance measures deemed important in the particular industry in which the firm operates. D'Aveni notes that when one refers to quality, one is referring to perceived quality of consumers. This is precisely what is measured in the Quest for Quality Survey. The second category of output is a hedonic measure of price. The basic premise of the hedonic pricing method is that the price of a marketed good is related to its characteristics or the services it provides. The applicability of this concept to motor carrier services is developed by Brown (1989). Again, this is captured by the Quest for Quality Survey. Customers benchmark the rates of a motor carrier against other carriers offering the same service as well ascertaining whether these rates are commensurate with the service level required by the customer.

To understand the relationship between customers' service demand and the factors of price and quality, one needs to understand how the relative proportions of these factors affect service demand. That is, one needs a measure of how customers prioritize price relative to quality, or in other words, a price-quality composite measure that is the functional determinant of service demand. The theoretical basis for this prioritization is found in the Kano framework outlined above. The level of magnitude of this price-quality composite measure implicitly determines customer demand.

The customer assigned weights in the weighted rating scores calculated in the Quest for Quality Survey provide the basis of such a composite measure. Customers assess motor carriers in five critical areas of service price and quality: performance, value, information technology, customer service, and equipment and operations. These are detailed above. Customers rate each of the five areas on a 1-to-3 scale: 3 = outstanding, 2 = average, $1=$ poor. At the same time, customers are asked to rank, by importance, each of the five areas on a 1-to5 scale, with 5 being the most important and 1 being the least important. Weighted scores are then calculated by weighing each motor carrier's rating score $(1,2$, or 3 ) in each critical service price/quality area by the mean importance score in that area. A total weighted score is the sum of each of the five critical area weighted scores. Such a composite index provides a means of measuring overall customer satisfaction which reflects the priorities of customers. Thus, a realized value for this weighted score is a proxy for the price-quality composite measure which in turn determines the realized demand for a given motor carrier's services.

The input variables that determine the levels of price and quality are the five motor carrier strategic foci variables referred to above. These are not chosen for convenience, but as detailed above, reflect a considerable body of empirical literature detailing the relationship between each strategic focus and motor carrier performance. Effectively, each strategy focus represents a par- 
ticular approach or production method to achieve a particular combination of price and quality as measured above. Effectively, each strategic focus reflects a commitment of resources towards its implementation. A particular motor carrier may choose a single strategic focus. More characteristically, a motor carrier will probably choose a "blending" or composite production method of strategic foci to generate a combination of price and quality. Thus there is a direct linkage between the levels of motor carriers' strategic foci variables and the price-quality composite measure that determines customer demand. Specifically, the demand for a motor carrier's services, Q is defined by:

$$
\mathrm{Q}=\mathrm{Q}\left[\mathrm{g}\left(\mathrm{p}, \mathrm{q}_{\mathrm{i}}\right)\right]=\mathrm{f}\left(\mathrm{s}_{\mathrm{j}}\right)
$$

where $p$ is the realized value of price, $q_{i}$ the realized level of the ith quality attribute $(1=$ $1, \ldots .5)$ and $s_{j}$ is the realized measure of jth strategic focus $(j=1, \ldots, 7)$. The function $g\left(p, q_{i}\right)$ is the price-quality composite measure. Relative efficiency in the production of particular levels of price and quality is measured in terms of the choice of a particular blending of strategic foci by a motor carrier relative to other carriers in the industry.

Notice that this "blending" of strategic foci allows for a richer and more complex interaction between price and quality. Conventional wisdom would suggest that higher service quality will cost more to produce and so one would expect to see higher prices and higher total revenue that might not translate into higher profits. However, two motor carriers exhibiting the same levels of service quality may be achieving this level with very different blends or configurations of their strategic foci. Even if both configurations are efficient, as defined below, one may be a lower cost blend than the other, thus allowing that motor carrier the ability to charge a lower price. Depending upon the elasticity of demand on the part of customers, it is conceivable that the motor carrier with the lower price might very well earn higher profits.

The relationship between combinations of strategic orientations and levels of customer satisfaction can be described in the framework of microeconomic production theory. Such theory utilizes the concept of a production possibility set (or production frontier) which in the current study consists of the feasible combinations of inputs (strategic dimension intensities) and output (level of customer satisfaction as measured by a carrier's weighted score). Data envelopment analysis (DEA) was used to generate a "best practice" production frontier given observed values of inputs and output for the motor carriers in the sample. A motor carrier operating on this best practice frontier is producing the maximum level of output (customer satisfaction) given chosen levels of inputs (strategic dimension intensities). Motor carriers with combinations of inputs and output that lie inside this frontier are inefficient. Thus, the efficiency of a motor carrier's selected portfolio of strategic foci is defined relative to the other motor carriers under consideration.

\section{DATA AND METHODOLOGY}

The current, preliminary study utilizes a sample of 21 LTL motor carriers. This sample was dictated by both the existence of data for a motor carrier in the American Trucking Association's (ATA) comprehensive financial and operating statistics database and the carrier's inclusion in the Quest for Quality Survey. Note that the number of LTL carriers in the ATA database is considerably smaller than the number of such carriers in the Quest for Quality Survey. The year studied was 2002 as it represented the most recent data available from the ATA. The Quest for Quality Survey, which provided values for the weighted customer satisfaction scores described above, is the most extensive market research study conducted in the logistics industry and done by Reed Research Group for Logistics Management. Specifically, for all categories of LTL motor carriers, there were 1,166 respondents for the year 2002. Values for the input variables (strategic dimensions) were calculated in the same manner as the previous studies described above, utilizing the ATA database. In calculating these strategic focus variables, values for the years 2001 and 2002 were averaged in order to allow sufficient time for a strategic dimension to impact customer satisfaction.

The DEA model utilized in this study is the input-oriented model described by Ali and Seiford (1993). This model is much akin to that 
LTL Motor Carrier Industry

of Charnes et al. (1978). The input-oriented model calculates a measure of input efficiency, IOTA. The value 1 minus IOTA is the total proportional reduction in inputs an inefficient motor carrier could undertake in order to reach the best practice frontier. An efficient motor carrier would have values of 1 for IOTA. In this case, 1 minus IOTA would be zero, indicating that zero proportional reduction in inputs was possible because such a motor carrier has indeed chosen an efficient combination of inputs. The software utilized for the DEA analysis was the Integrated Data Envelopment Analysis System, developed by 1 Consulting.

\section{RESULTS}

Table 1a provides a list of the trucking companies. Table $1 \mathrm{~b}$ highlights the fact that many of these motor carriers have been Quest for Quality winners over the years 1999 to 2002. An LTL motor carrier is determined to be a Quest for Quality winner if its total weighted score exceeds the average weighted score for all LTL motor carriers in the survey.

Table 2 presents the complete dataset utilized in this study. As noted above, the seven dimensions of operating strategies were used to define the strategic orientations of motor carriers. Table 3 presents the descriptive statistics for the seven strategic foci variables. In Table 4 Pearson correlation coefficients and their statistical significance are presented. The observed correlations suggest that in achieving greater efficiency, motor carriers incur lower costs. At the same time, higher costs are associated with higher prices to customers. The pursuit of a service or niche orientation is also associated with higher costs. Finally, while the size of a motor carrier seems to be associated with higher levels of service, such size is also associated with higher costs similar to the direct positive correlation between cost and service.

Remember, however, that these relationships are not the focus of this study. As noted above, this study is not an investigation of whether motor carriers have identified, for themselves, a single best combination of strategic foci. Rather, what is being investigated is the relative efficiency of motor carriers" "blending" choices of strategic foci.

Table 1a: Sample Membership
\begin{tabular}{|l|}
\hline NAME \\
\hline AAA Cooper Transportation \\
\hline ABF Freight Systems \\
\hline Averitt Express Inc. \\
\hline Central Freight Lines \\
\hline Estes Express Lines \\
\hline Jevic Transportation Inc. \\
\hline New England Motor Freight Inc. \\
\hline New Penn Motor Express Inc. \\
\hline Old Dominion Freight Line Inc. \\
\hline Overnite Transportation Company \\
\hline Pitt Ohio Express LLC \\
\hline Roadway Express Inc. \\
\hline Saia Motor Freight Lines Inc. \\
\hline Southeastern Freight Lines Inc. \\
\hline USF Dugan Inc. \\
\hline USF Holland Inc. \\
\hline USF Reddaway Inc. \\
\hline Ward Trucking Corporation \\
\hline Watkins Motor Lines Inc. \\
\hline Wilson Trucking Corporation \\
\hline Yellow Transportation Inc. \\
\hline
\end{tabular}

Table 5 highlights the fact that the sample LTL carriers did not demonstrate a consistent pattern of strategic foci. For the price, efficiency, niche, service, size and risk dimensions, a carrier was said to have a particular focus if it was more than one standard deviation above the sample mean for that dimension. For the cost dimension, a carrier was deemed to have a focus if it was more than one standard deviation below the sample mean. Eight LTL motor carriers displayed no focus, six displayed a single focus, and seven displayed two or three foci. This provides further motivation to investigate the relative efficiencies of motor carriers' configuration of their strategic dimension intensities.

Table 6 reinforces this motivation by suggesting that there is a statistically significant relationship between a motor carrier's weighted quality-of-service score and its performance as measured by its operating ratio (total operating costs divided by total operating revenues). The sample of motor carriers was divided into two groups - those above the median and those at or below the median for the weighted quality of service score. A Tukey studentized range test was performed to examine whether there was 
LTL Motor Carrier Industry

Table 1b: Sample Motor Carriers - Quest for Quality Winners
\begin{tabular}{|l|c|c|c|c|}
\hline NAME & $\mathbf{2 0 0 2}$ & $\mathbf{2 0 0 1}$ & $\mathbf{2 0 0 0}$ & $\mathbf{1 9 9 9}$ \\
\hline AAA Cooper Transportation & $\mathrm{X}$ & $\mathrm{X}$ & $\mathrm{X}$ & $\mathrm{X}$ \\
\hline ABF Freight System Inc. & $\mathrm{X}$ & $\mathrm{X}$ & $\mathrm{X}$ & $\mathrm{X}$ \\
\hline Averitt Express Inc. & & $\mathrm{X}$ & & $\mathrm{X}$ \\
\hline Jevic Transportation Inc. & $\mathrm{X}$ & $\mathrm{X}$ & $\mathrm{X}$ & $\mathrm{X}$ \\
\hline New Penn Motor Express Inc. & $\mathrm{X}$ & $\mathrm{X}$ & $\mathrm{X}$ & $\mathrm{X}$ \\
\hline Pitt Ohio Express LLC & $\mathrm{X}$ & $\mathrm{X}$ & $\mathrm{X}$ & $\mathrm{X}$ \\
\hline Roadway Express Inc. & $\mathrm{X}$ & & & \\
\hline Saia Motor Freight Line Inc. & $\mathrm{X}$ & $\mathrm{X}$ & $\mathrm{X}$ & $\mathrm{X}$ \\
\hline Southeastern Freight Lines Inc. & $\mathrm{X}$ & $\mathrm{X}$ & $\mathrm{X}$ & $\mathrm{X}$ \\
\hline USF Holland Inc. & $\mathrm{X}$ & $\mathrm{X}$ & $\mathrm{X}$ & $\mathrm{X}$ \\
\hline USF Reddaway Inc. & $\mathrm{X}$ & $\mathrm{X}$ & $\mathrm{X}$ & $\mathrm{X}$ \\
\hline Ward Trucking Corporation & & $\mathrm{X}$ & $\mathrm{X}$ & $\mathrm{X}$ \\
\hline Watkins Motor Lines Inc. & $\mathrm{X}$ & $\mathrm{X}$ & $\mathrm{X}$ & $\mathrm{X}$ \\
\hline Yellow Transportation Inc. & & & & \\
\hline
\end{tabular}

a statistically significant difference in the mean values of the operating ratio for the two groups. In the current study, there is a problem in that the groups are of unequal size. This requires that an extension of the test proposed by Tukey $(1952,1953)$ be used. The original Tukey test (1952) was designed specifically for pair wise comparisons based on the studentized range, and controls the maximum experiment wise error rate (MEER) when the sample sizes are equal. Tukey (1953) and Kramer (1956) independently proposed a modification for unequal cell sizes. The Tukey-Kramer method, as used in this study, has fared extremely well in Monte Carlo studies (Dunnett 1980). Additionally, Hayter (1984) provides a proof that the Tukey-Kramer procedure controls the MEER.

Specifically, two means are considered significantly different by the Tukey-Kramer criterion if:

(2) $\left|y_{i} y_{j}\right| / s \sqrt{\left(1 / n_{i} 1 / n_{j}\right) / 2} \quad \mathrm{q}(\alpha ; \kappa, v)$

where $\mathrm{q}(\alpha, K, \nu)$ is the $\alpha$-level critical value of a studentized range distribution of $\kappa$ independent normal random variables with $\nu$ degrees of freedom. The software utilized is the GLM procedure in the SAS software package (2002), which calculates significance for the TukeyKramer statistic at the 5\% level. Those motor carriers above the median had a significantly lower operating ratio implying higher operating profits

Table 7 presents the results of the data envelopment analysis. Recall that efficient carriers have scores of 1 for IOTA. Of the $21 \mathrm{LTL}$ motor carriers in the sample, 10 were utilizing efficient combinations of strategic dimension intensities and 11 were not. Some of the values of IOTA are quite revealing. If an inefficient motor carrier exhibits a value of IOTA close to one, it can remain with its current combination of strategic dimension intensities and simply pursue a small proportional scaling down of its input levels to achieve the best practice frontier. However, if IOTA is much less than one, then there is the suggestion that such a motor carrier needs to reconsider the combination of strategic dimension intensities it has chosen. In the nomenclature of economic production theory this is equivalent to saying a firm needs to consider choosing a new production technology. Such is the case for AAA Cooper Transportation (0.85), ABF Freight System Inc. (0.79), Central Freight Lines (0.83), Overnite Transportation Company (0.77), Roadway Express Inc. (0.57), Saia Motor Freight Line Inc. (0.86), and Yellow Transportation Inc. (0.74).

Table 8 divides the sample into three groups: IOTA equal to 1.00 (efficient), IOTA greater than or equal to 0.90 but less than 1.00 (mildly inefficient), and IOTA less than 0.90 (severely 


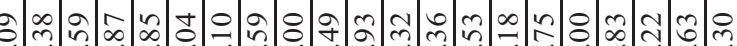

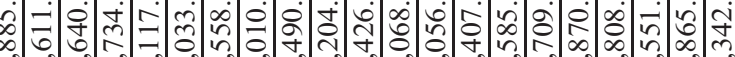
ڤी

떵

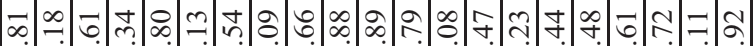

$\geqslant 2$ సి పే

된

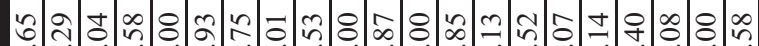

$\frac{v}{4}$

$\simeq$

毀

乙

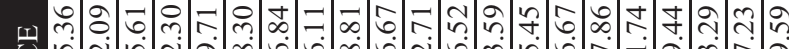

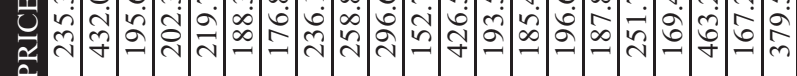

ชิธิ์

를

ชิ

ֻே

$\stackrel{2}{\check{2}}$

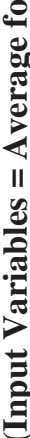

है

唯

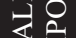

o

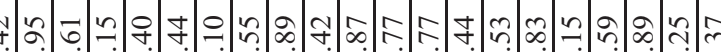

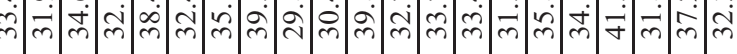

\section{.}

ก

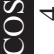

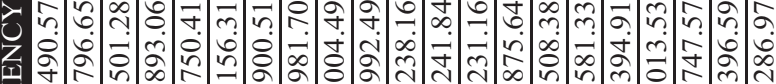

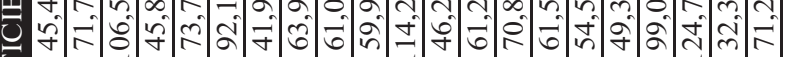

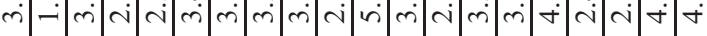

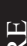

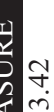
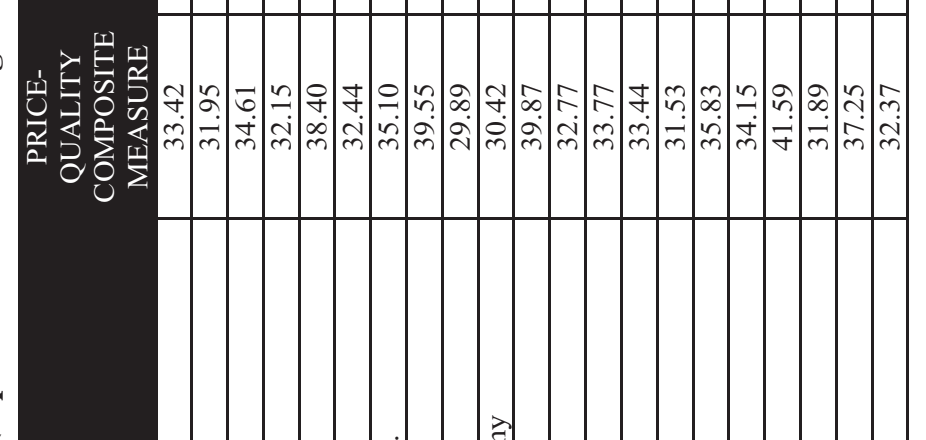

离
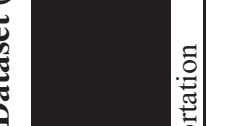

$\frac{0}{2}$

है

$\ddot{\sim}$

产

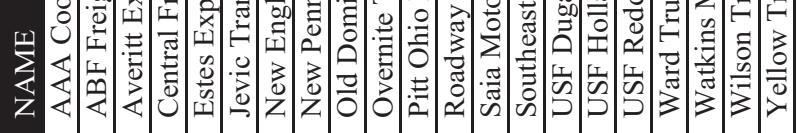



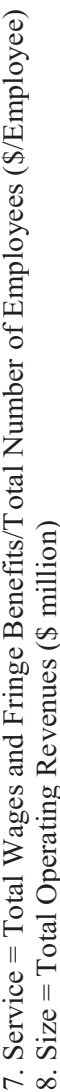



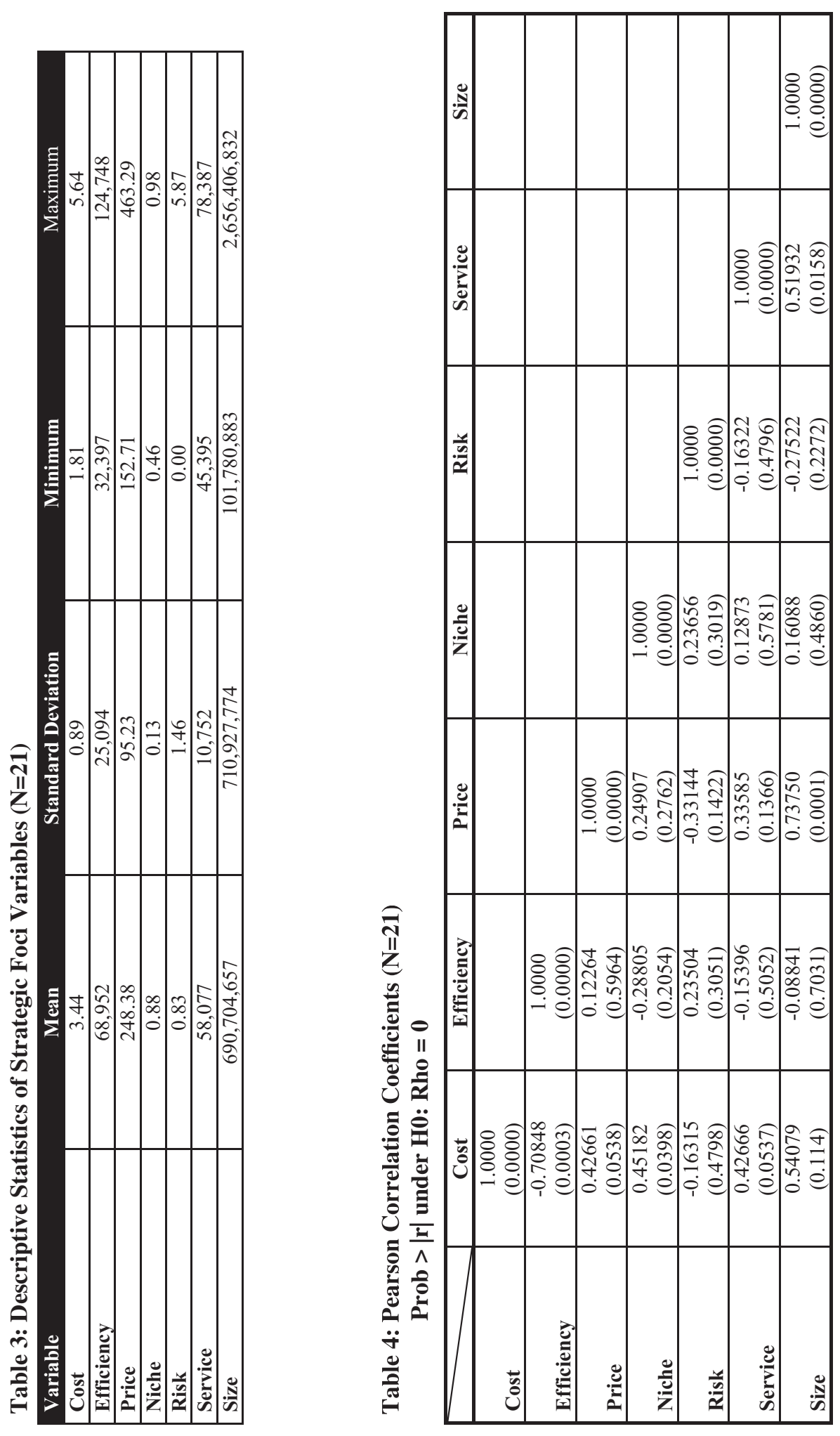

82 


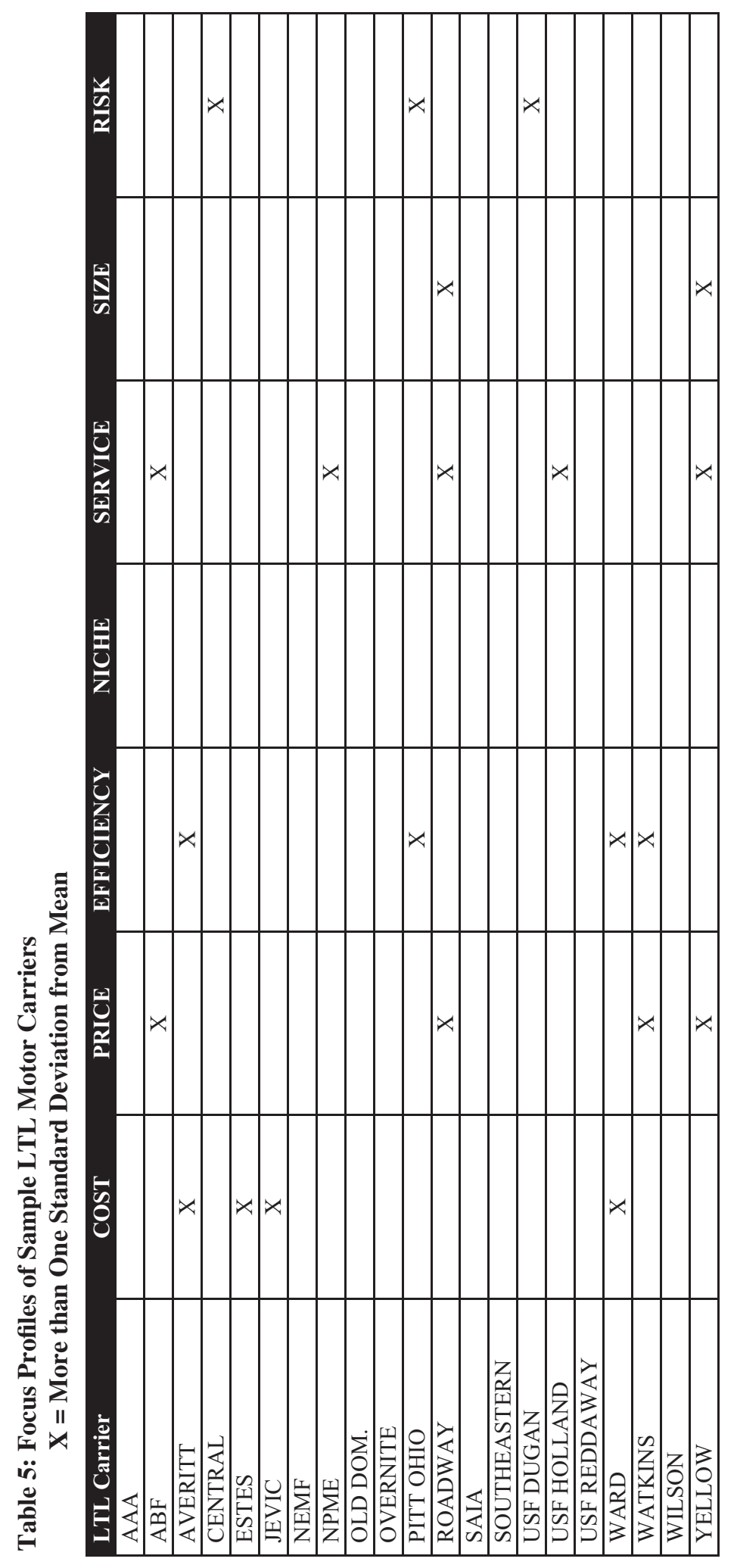


LTL Motor Carrier Industry

\begin{tabular}{|c|c|c|}
\hline Group & Mean & Significance \\
\hline 2 & 93.23 & $* * *$ \\
\hline 1 & 96.18 & $* * *$ \\
\hline
\end{tabular}

Table 7: DEA Efficiency Scores of Motor Carriers

\begin{tabular}{|l|c|}
\hline NAME & IOTA \\
\hline AAA Cooper Transportation & 0.85 \\
\hline ABF Freight System Inc. & 0.79 \\
\hline Averitt Express Inc. & $\mathbf{1 . 0 0}$ \\
\hline Central Freight Lines Inc. & 0.83 \\
\hline Estes Express Lines & $\mathbf{1 . 0 0}$ \\
\hline Jevic Transportation Inc. & $\mathbf{1 . 0 0}$ \\
\hline New England Motor Freight Inc. & $\mathbf{1 . 0 0}$ \\
\hline New Penn Motor Express Inc. & $\mathbf{1 . 0 0}$ \\
\hline Old Dominion Freight Line Inc. & 0.92 \\
\hline Overnite Transportation Company & 0.77 \\
\hline Pitt Ohio Express LLC & $\mathbf{1 . 0 0}$ \\
\hline Roadway Express Inc. & 0.57 \\
\hline Saia Motor Freight Line Inc. & 0.86 \\
\hline Southeastern Freight Lines Inc. & $\mathbf{1 . 0 0}$ \\
\hline USF Dugan Inc. & 0.95 \\
\hline USF Holland Inc. & 0.94 \\
\hline USF Reddaway Inc. & 0.91 \\
\hline Ward Trucking Corporation & $\mathbf{1 . 0 0}$ \\
\hline Watkins Motor Lines Inc. & $\mathbf{1 . 0 0}$ \\
\hline Wilson Trucking Corporation & $\mathbf{1 . 0 0}$ \\
\hline Yellow Transportation Inc. & 0.74 \\
\hline
\end{tabular}

inefficient). A Tukey studentized range test, as described above, revealed that weighted qualityof-service scores were statistically significantly lower for severely inefficient motor carriers as compared to the efficient group.

Table 9 investigates the relationship between input efficiency as measured by IOTA and levels of strategic dimension intensities. The intent here is to examine whether certain strategic foci are more likely to be associated with input inefficiency. If such is the case, a motor carrier using a blend of such strategic foci would need to be especially vigilant in its allocation of resources. IOTA is a censured variable both below and above, i.e. $0 \leq$ IOTA $\geq 1$. A transformation suggested by Fethi et al. (2002) and utilized by Scheraga (2004a, 2004b) is employed to transform IOTA into a left-censured variable, thus allowing a tobit analysis. This new variable is defined as (1/ IOTA) - 1 which is greater than or equal to zero in a continuous fashion. For the transformed value of IOTA, an efficient motor carrier will have a value of zero, while an inefficient motor carrier will have a value greater than zero. Thus variables positively correlated with IOTA will be negatively correlated with the transformed value of IOTA. Four statistically significant relationships were observed. In the sample of motor carriers in this study, higher levels for the 
LTL Motor Carrier Industry

\begin{tabular}{|c|c|c|c|}
\hline \multicolumn{4}{|c|}{$\begin{array}{l}\text { Table 8: Tukey's Studentized Range Test } \\
\text { Differences in Quality Scores by Input Effiiency (IOTA) Groups } \\
\text { (Group 3: IOTA = 1.00; Group 2: 0.90 } \leq \text { IOTA < 1.00; Group } 1 \\
\text { (Comparisons significant at the } 0.05 \text { level are indicated by ***) }\end{array}$} \\
\hline Group Comparison & $\begin{array}{c}\text { Difference between } \\
\text { Means }\end{array}$ & $\begin{array}{l}\text { Simultaneous } 95 \% \\
\text { Confidence Limits }\end{array}$ & Significance \\
\hline 12 & 0.443 & $4.768 \quad 3.883$ & \\
\hline 13 & 4.007 & 0.606 & $* * *$ \\
\hline 3 & 3.564 & 7.647 & \\
\hline
\end{tabular}

Table 9: Regression Results - Tobit Model

Dependent Variable: Transformed IOTA $2000=(1 /$ IOTA 2000 $)-1$

Standardized Independent Variables

\begin{tabular}{|l|c|c|c|c|}
\hline Variable & Estimate & Std. Error & Chi Square & Pr $>$ Chi Square \\
\hline Intercept & 0.0450 & 0.0307 & 2.1425 & 0.1433 \\
\hline Cost & 0.0601 & 0.0599 & 1.0061 & 0.3158 \\
\hline Price & $\mathbf{0 . 0 8 4 1}$ & $\mathbf{0 . 0 4 6 4}$ & $\mathbf{3 . 2 8 5 4}$ & $\mathbf{0 . 0 6 9 9}$ \\
\hline Efficiency & $\mathbf{0 . 1 1 5 2}$ & $\mathbf{0 . 0 6 5 1}$ & $\mathbf{3 . 1 3 5 1}$ & $\mathbf{0 . 0 7 6 6}$ \\
\hline Niche & 0.0009 & 0.0434 & 0.0004 & 0.9833 \\
\hline Service & 0.0155 & 0.0263 & 0.3495 & 0.5544 \\
\hline Size & $\mathbf{0 . 1 1 4 6}$ & $\mathbf{0 . 0 3 6 0}$ & $\mathbf{1 0 . 1 4 3 0}$ & $\mathbf{0 . 0 0 1 4}$ \\
\hline Risk & $\mathbf{0 . 0 6 9 7}$ & $\mathbf{0 . 0 3 0 0}$ & $\mathbf{5 . 3 8 0 6}$ & $\mathbf{0 . 0 2 0 4}$ \\
\hline
\end{tabular}

efficiency dimension were associated with higher levels of IOTA. However, higher levels for the price, size, and risk dimensions were associated with lower levels of IOTA.

\section{CONCLUSIONS}

By using Table 2 and Table 5, one can see that "best practice" LTL motor carriers exhibited a variety of different "portfolios" with regard to their configuration of strategic dimension intensities. Carriers such as Central Freight Lines, Estes Express Lines, Jevic Transportation, New Penn Motor Express, USF Dugan, and USF Holland had a single strategic focus. Companies such as ABF Freight System, Averitt Express, Pitt Ohio Express, Roadway Express, Ward Trucking, Watkins Motor Lines, and Yellow Transportation had two or more strategic foci. Finally, carriers such as AAA Cooper Transportation, New England Motor Freight, Old Dominion Freight Line, Overnite Transportation, Saia Motor Freight Lines, Southeastern Freight Lines, USF Reddaway, and Wilson Trucking Corporation had no dominant strategic focus, but exhibited a "blending" across the seven strategic dimensions. This suggests that Porter's sharply delineated categories of generic strategies may not accurately capture the nature of competition in the LTL motor carrier industry.

The study empirically verified the intuitive notion that there is a positive relationship between the level of the quality of service and firm profitability as measured by the operating ratio. Additionally, evidence was found to suggest that the efficiency of a motor carrier's strategic dimension intensities configuration had a significant impact on the level of service quality realized by customers. Furthermore, it was demonstrated that certain strategic dimensions (price, size, and risk) were more likely to cause a motor carrier to be below the best practice frontier.

In line with this last observation regarding the size focus, economies of scale, as reflected in the size dimension, may not have the usual positive effect when it comes to perceived quality of service. In fact, this was suggested in commentary provided by the 1996 Quest for Quality Survey. Customers perceived 
the smaller, regional carriers as being more responsive. They better understood the business of their customers and were able to provide personalized service with more flexibility in their operations. There also was the perception that such an understanding of the customer was impeded by the numerous levels of people encountered when dealing with large carriers. In addition, while customers acknowledged that the larger LTL carriers had better transit times from terminal to terminal, the smaller regional LTL carriers held an advantage in times from shipper to customer.

It must also be noted, that as shown in Table 2 , there are motor carriers who are financing themselves with high levels of debt relative to equity. Such behavior might inherently hinder such motor carriers from achieving efficient blends of strategic foci. One might suspect this in light of the study done by Zingales (1998). He examined the effect of the pre-deregulation level (1977) of leverage on the survival of trucking firms in the deregulated period (1985). He found that highly leveraged carriers were less likely to survive deregulation, even after controlling for various measures of efficiency. High debt seemed to reduce carriers' ability to undertake investments and reduced the price per ton that carriers could charge.

As noted above, this study is preliminary in nature. Inclusion in the sample of motor carriers used in this study required membership in two datasets. The number of LTL motor carriers in the ATA database has declined because of bankruptcies, consolidations, and the more "voluntary" nature of company reporting. This latter phenomenon and the problem of missing data items was a key reason the number of carriers available for study was less than those reported in the Quest for Quality Survey. Nevertheless, the results of this study demonstrate that the data envelopment analysis methodology provides carriers with a means of regularly benchmarking their strategic orientations as well as identifying the competitors against whom such benchmarking should occur. Finally, the methodology of this study could be applied to other sectors of the motor carrier industry.

\section{References}

Ali, A. and L. Seiford. "The Mathematical Programming Approach to Efficiency Analysis.” H.

Fried, C. Lovell, and S. Schmidt eds. The Measurement of Productive Efficiency. New York, NY: Oxford University Press (1993): 120-159.

American Trucking Associations, Inc. Motor Carrier Annual Reports. Alexandria, VA: 20012002.

Brown, D. "Freight Service Quality and Carrier Economics." Journal of the Transportation Research Forum 30 (1), (1989): 141-152.

Cahners Research (Reed Business Information). Logistics Management \& Distribution Report: Quest for Quality Survey. New York, NY: 1997, 2003.

Charnes, A., W. Cooper, and E. Rhodes. "Measuring the Efficiency of Decision Making Units." European Journal of Operational Research 2 (6), (1978): 429-444.

Child, J. "Managerial and Organizational Factors Associated with Company Performance.

Part 1." Journal of Management Studies 11 (3), (1974): 175-218.

Chow, G. and R. Poist. "The Measurement of Quality of Service and the Transportation Purchase Decision." Logistics and Transportation Review 20 (1), (1984): 25-44. 
LTL Motor Carrier Industry

Corsi, T. and C. Grimm. "Strategies and Performance in the Truckload General Freight Segment Before and After Deregulation." Journal of the Transportation Research Forum 30 (1), (1989): 84-91.

Corsi, T., C. Grimm, K. Smith, and R. Smith. "Deregulation, Strategic Change, and Firm Performance among LTL Motor Carriers." Transportation Journal 31 (1), (1991): 4-13.

D'Aveni, R. Hypercompetition: Managing the Dynamics of Strategic Maneuvering. Free Press, New York, NY, 1994.

Dunnett, C. "Pairwise Multiple Comparisons in the Homogeneous Variance, Unequal Sample Size Case." Journal of the American Statistical Association 75, (1980): 789-795.

Feitler, J., T. Corsi, and C. Grimm. "Measuring Firm Strategic Change in the Regulated and Deregulated Motor Carrier Industry: An 18 Year Evaluation.” Transportation Research Series E 33 (3), (1997): 159-169.

Fethi, M., P. Jackson, and T. Weyman-Jones. "Measuring the Efficiency of European Airlines: An Application of Tobit Analysis." Working Paper, University of Leicester, Management Center (2002).

Hayter, A. "A Proof of the Conjecture that the Tukey-Kramer Method is Conservative." The Annals of Statistics 12, (1984): 61-75.

Holcomb, M. and K. Manrodt. "The Shippers' Perspective: Transportation and Logistics Trends and Issues.” Transportation Journal 40 (1), (2000): 15-25.

Kano, N., N. Seraku, F. Takahashi, and S. Tsuji. "Attractive Quality and Must-be Quality.” The Journal of the Japanese Society for Quality Control, April (1993): 39-48.

Kleinsorge, I., P. Schary, and R. Tanner. "The Shipper-Carrier Partnership: A New Tool for Performance Evaluation.” Journal of Business Logistics 12 (20), (1991): 35-57.

Kramer, C. "Extension of Multiple Range Tests to Group Means with Unequal Numbers of Replications." Biometrics 12, (1956): 307-310.

Lambert, D., M. Lewis, and J. Stock. "Customer-Focused Strategies for Motor Carriers." Transportation Journal 32 (4), (1993): 21-28.

McGinnis, M. "The Relative Importance of Cost and Service in Freight Transportation Choice: Before and After Deregulation.” Transportation Journal 30 (1), (1990): 112-119.

1 Consulting. Integrated Data Envelopment Analysis System, Version 6.1.7. Amherst, MA, 2000.

Porter, M. Competitive Strategy: Techniques for Analyzing Industries and Competitors. The Free Press, New York NY, 1980.

Premeaux, S. "Motor Carrier Selection Criteria: Perceptual Differences Between Shippers and Motor Carriers." Transportation Journal 42 (2), (2002): 28-38. 
SAS Institute, Inc. SAS/STAT User's Guide, Version 8. Cary, North Carolina, 2002.

Scheraga, C., J. Haslem, and T. Corsi. "The Financial Mobility of Motor Carriers: Pre- and PostDeregulation.” Transportation Research Series A 28 (5), (1994): 410-414.

Scheraga, C. "Operational Efficiency versus Financial Mobility in the Global Airline Industry: A Data Envelopment and Tobit Analysis.” Transportation Research Series A 38 (5), (2004): 383 404.

Scheraga, C. "The Relationship Between Operational Efficiency and Customer Service: A Global Study of Thirty-Eight Large International Airlines." Transportation Journal 43 (3), 2004: 48-58.

Smith, K., T. Corsi, and C. Grimm. "Motor Carrier Strategies and Performance." Transportation Research Series A 24 (3), (1990): 201-210.

Smith, R., T. Corsi, C. Grimm, and K. Smith. "The Effects of LTL Motor Carrier Size on Strategy and Performance." Logistics and Transportation Review 28 (2), (1992): 129-146.

Tukey, J. “Allowances for Various Types of Error Rates.” Unpublished IMS Address, Chicago, Illinois, (1952).

Tukey, J. “The Problem of Multiple Comparisons.” Unpublished Manuscript, (1953).

Zingales, L. "Survival of the Fittest or Fattest? Exit and Financing in the Trucking Industry." Journal of Finance 53 (3), (1998): 905-938.

Carl A. Scheraga is associate professor of business strategy and technology management. His fields of research and teaching include transportation and international logistics, global strategic management, cross-cultural management, and the management of technology and iinovation. Scheraga received his Ph.D. in Economics from the University of Connecticut, an M.A. in Economics, and a Sc.B in Mathematics and Engineering from Brown University. 